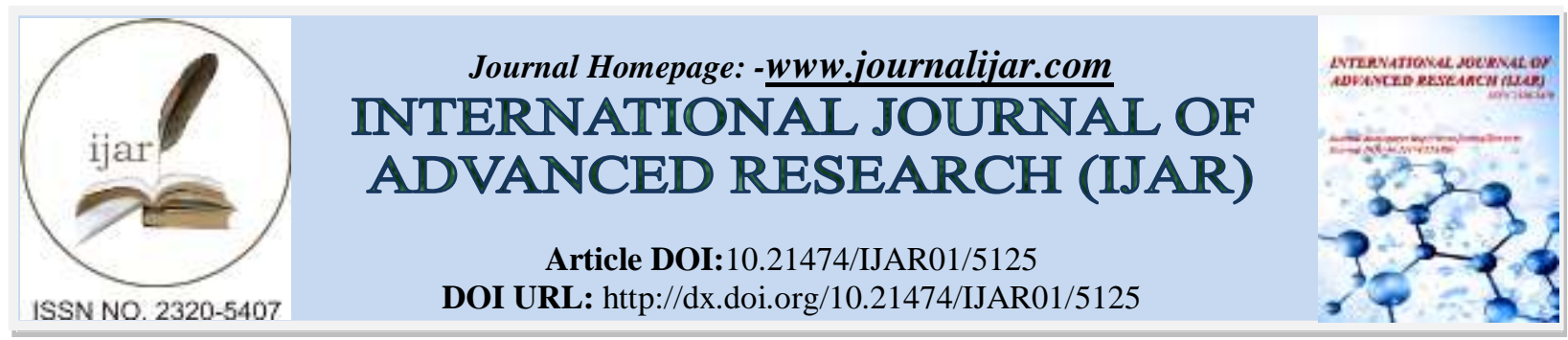

RESEARCH ARTICLE

\title{
EFFECT OF APPLICATION OF NATURALLY OCCURRING ANTI-OXIDANT AGENTS ON BONDING OF COMPOSITE RESIN TO BLEACHED ENAMEL- AN IN-VITRO STUDY.
}

\section{Dr. Ashok HK, Dr. Roopa R Nadig, Dr. K Rashmi, Dr. Vedavathi, Dr. Veena S Pai, Dr. Swapna DV.}

\section{Manuscript Info}

(..........................

Manuscript History

Received: 10 June 2017

Final Accepted: 12 July 2017

Published: August 2017

Key words:-

Tooth bleaching, pomegranate seed, tomato seed extract.

\section{Abstract}

Background: With the minimal invasive concepts gaining popularity, vital tooth bleaching is well accepted treatment with predictable outcome.

One of the disadvantages of tooth bleaching is decreased bond strength of composite resin to enamel. Antioxidants are used to get back the decreased bond strength.

Aim of the study: was to investigate, the effect of immediate application of three anti-oxidant agents on reversal of decreased bond strength of composite resin to bleached enamel \& to evaluate and compare the resin enamel interface with and without the use of antioxidants using SEM.

Materials and Methods: Labial enamel surfaces of 50 extracted human maxillary central incisors were randomly divided into five groups based on the antioxidant used, Group I $(n=10)$ : negative control, Group II ( $\mathrm{n}=10)$ : positive control, Group III $(\mathrm{n}=10)$ : bleaching followed by $10 \%$ sodium ascorbate solution application , Group IV $(\mathrm{n}=10)$ : bleaching followed by 5\% pomegranate seed extract application, Group V $(\mathrm{n}=10)$ : bleaching followed by $5 \%$ tomato seed extract application. Each specimen was tested for shear bond strength. Two specimens from each group were selected for scanning electron microscopic (SEM) observation to assess resin enamel interface.

Results: Significantly higher shear bond strength values were observed in Group IV, Group V as compared with the control groups, Group I and II. SEM analysis also proved the above results.

Conclusion: It can be concluded that the use of tomato seed extract and pomegranate seed extract can be used as an alternative to sodium ascorbate prior to bonding procedures on bleached enamel.

Copy Right, IJAR, 2017,. All rights reserved.

\section{Introduction:-}

Increase in the demand for aesthetic dentistry \& with the minimal invasive concepts gaining popularity, vital tooth bleaching is well accepted treatment with predictable outcome. However, bleaching alone fails to enhance esthetics, so additional adhesive procedures like composite restorations, ceramic veneers are often required. ${ }^{1}$

There are few disadvantages of teeth bleaching like post-operative sensitivity, pulp irritation, tooth structure alteration, micro leakage and decreased bond strength of composite resin to enamel. ${ }^{2}$ 
To overcome the decreased bond strength, various techniques have been propagated such as, removal of superficial enamel; treatment of enamel with alcohol, delaying bonding procedures and use of various antioxidants. Sodium ascorbate is an antioxidant that is considered gold standard. Time of application of ascorbic acid as reported in the literature ranges from $10 \mathrm{~min}$ to $3 \mathrm{hrs}$ to obtain satisfactory results. ${ }^{3-6} \mathrm{~A}$ quest to look for an alternative anti-oxidant has led to a search of naturally available antioxidants such as green tea, grape seeds extract, pomegranate seed extract, and tomato seed extract, etc, which appear to have shown more efficient antioxidant property and also safer and economical. ${ }^{7}$

Therefore newer naturally available antioxidants are being investigated as an alternative replacement to sodium ascorbate. Hence the present study was designed to investigate, the effect of immediate application of naturally available anti-oxidant agents on reversal of bond strength to bleached enamel and to observe the changes that occur at the resin enamel interface. The Null hypothesis postulated was, there was no change in the bond strength of composite resin to bleached enamel following immediate application of antioxidants.

\section{Materials and methods:-}

It's an in-vitro trial involving extracted maxillary central incisors. 50 freshly extracted non carious human maxillary incisors extracted due to periodontal problems were collected from the Department of Oral and Maxillofacial Surgery, Dayananda Sagar College of Dental Sciences, after taking patient consent.

\section{Preparation of specimens:-}

The specimens were cleaned of any tissue, plaque or calculus and the roots were sectioned $3 \mathrm{~mm}$ beyond CEJ apically, and pulp chamber was cleaned using spoon excavators, sodium hypochlorite and saline.

The crown segments were embedded in self cure resin with exposed enamel surface. The labial surfaces were ground flat and polished with 600-grit sand paper or silicon carbide abrasive disc for 60 seconds to create a flat enamel surface. The specimens were stored in artificial saliva and randomly divided into five groups of 10 teeth each.

Group I : No bleaching/antioxidant application -Negative control

Group II: Bleaching only, no antioxidant application- Positive control

Group III: Bleaching followed by $10 \%$ sodium ascorbate application for 10 minutes.

Group IV: Bleaching followed by $5 \%$ pomegranate seed extract application for 10 minutes.

Group V: Bleaching followed by $5 \%$ tomato seed extract application for 10 minutes.

\section{Preparation of solutions:-}

Three solutions were prepared to conduct this study:

- $10 \%$ sodium ascorbate was dissolved in $100 \mathrm{ml}$ of distilled water.

- $5 \%$ pomegranate seed solution was prepared by dissolving $5 \mathrm{~g}$ of pomegranate seed extract (powdered form) in $100 \mathrm{ml}$ of distilled water. (research lab of Department of Botany, Bangalore University)

- $5 \%$ tomato seed solution was prepared by dissolving $5 \mathrm{~g}$ of tomato seed extract (powder form) in $100 \mathrm{ml}$ of distilled water. (Research lab of Department of Botany, Bangalore University).

Bleaching was performed using 38\% hydrogen peroxide gel (Opalescence boost by Ultra-dent) applied for 20minutes, 2 applications in a day, according to manufactures instructions. Specimens were rinsed for 20 seconds after each application. $1 \mathrm{ml}$ of respective antioxidant solution was applied on the specified area of $3 \mathrm{~mm}$ diameter on each specimen for group III, IV, \& V. After antioxidant treatment the enamel surface was thoroughly rinsed with tap water for 30 seconds and air dried for 20 seconds.

All specimens were acid etched with $37 \%$ phosphoric acid for 15 seconds (D-tech), rinsed with water for 30 seconds and air dried for 20 seconds. A thin layer of adhesive (Adper single bond -3M) was applied on the etched enamel; gently blow dried and light cured (LED-monitex) for 10 seconds. On top of the specimens a plastic tubing of $3 \mathrm{~mm}$ diameter and $3 \mathrm{~mm}$ height was mounted. Two increments of composite resin (Filtek-Z 200, 3m - ESPE) were placed into the opening of the plastic tubing and each increment was light cured for $40 \mathrm{sec}$. After curing, the plastic tubing was removed. The specimens were stored in artificial saliva at $37^{\circ} \mathrm{c}$ for $24 \mathrm{hrs}$, prior to testing. 
Each specimen was seated on a universal testing machine (Lloyd -LR 50K) and shear load was applied to the base of the composite cylinder with a $1 \mathrm{~mm}$ thick knife edge rod, at a crosshead speed of $1 \mathrm{~mm} / \mathrm{min}$. The result was expressed in mpa.

Two specimens from each group were selected for scanning electron microscopic (SEM) observation to assess resin enamel interface.

Data was analyzed with SPSS using two - way ANOVA and Bonferroni tests. Significant level set at 0.5 (p value).

\section{Results:-}

Higher mean Shear Bond Strength was recorded in Group V followed by Group IV, Group III, Group I and Group II respectively.[fig 1,2,3,4 \& 5]. The difference in mean Shear Bond Strength among the groups was found to be statistically significant $(\mathrm{p}<0.001)$.

Multiple comparisons using Bonferroni test was carried out, to find out significant difference among the groups.

The difference in mean Shear Bond Strength was found to be statistically significant between Group I \& Group II ( $p<0.01)$, Group I \& Group III ( $p<0.001)$, Group I \& Group IV ( $<<0.001)$, group I \& Group V ( $<<0.001)$, Group II $\&$ Group III $(\mathrm{p}<0.001)$, Group II \& Group IV ( $<<0.001)$ as well as between Group II \& Group V ( $<<0.001)$. No significant difference was observed between Group III \& Group IV ( $>>0.05)$, Group III \& Group V (p>0.05) as well as between Group IV \& Group V ( $>0.05)$.

SEM analysis also proved the above results. SEM pictures of group II specimens clearly explain the underlying interaction at the tooth resin interface. It was observed that resin tags were fragmented and poorly defined and also penetrated to a lesser depth. The SEM pictures of the group III, IV and V specimen's showed evenly formed resin tags penetrating deeper into the enamel substrate.

\section{Discussion:-}

Improvements in bleaching agents, tooth colored restorations and bonding technology have made cosmetic dental procedures more palatable and feasible. Hydrogen peroxide is the most commonly used bleaching agent in different forms and concentrations. In-office bleaching with $38 \% \mathrm{H} 2 \mathrm{O} 2$ is the most popular and well accepted procedure especially patients who are looking at quick solutions. Hence the present study was designed incorporating the inoffice bleaching technique.

In 1994, Dishman and colleagues reported that following dissociation of the bleaching agent, a high concentration of oxygen remains among the enamel prisms and in the dentin. ${ }^{10}$

The dentin and dentinal fluid can act as peroxide and oxygen free radical reservoir and could persist until removed by pulpal microcirculation. In this perspective, this property could be deleterious during bonding of the composite resin, as higher levels of peroxide or oxygen may be present in the bonding surface, inhibiting the polymerization and, thus, reducing the bond strength. ${ }^{11}$

Hence, delay in bonding by 1-3 weeks following the bleaching procedure is recommended. However this rendered immediate reestablishment of further esthetic procedures impossible.

Lai et al stated that inclusion process of peroxide ions could be reversed by the use of antioxidants. Sodium ascorbate a derivative of ascorbic acid with neutral $\mathrm{pH}$, is a potent antioxidant capable of quenching reactive free radicals in biological systems. ${ }^{8}$

With regards to the time of application of sodium ascorbate, several authors have suggested different time periods ranging from 10min to $3 \mathrm{hrs}$. In a study done by Lai et al in the year 2002, showed reversal of bond strength after the bleached specimens were immersed in $10 \%$ sodium ascorbate solution for $3 \mathrm{hrs}{ }^{8-10}$ 
10 min application of all the experimental groups has been used in this study based on the research work carried out by Vidya et al and Mageshwaran et al where they showed 10min surface treatment is effective and also clinically feseable especially for patients who have opted for in-office bleaching procedures. ${ }^{11,12}$

Although many natural extracts have been identified to have antioxidant property, pomegranate and tomato extracts seem to have shown very high potential as antioxidants and therefore these agents were selected for the study.

5\% concentration of Pomegranate and tomato seed extract for 10 minutes was used in the present study, based on the study done by Farahnaz Sharafeddin et al and Yu Zao et al who have investigated the effect of pomegranate seed extract and tomato fruit extract respectively and have reported desirable results. ${ }^{12-14}$

In this study Shear bond strength was evaluated rather than tensile mode of testing, as it would accurately reflect the type of forces generated on resin restorations in the anterior teeth. ${ }^{15,16}$

Results of the current study showed higher mean shear bond strength in group V (43.50MPa) followed by group IV (42.93MPa), III (38.34MPa), I(21.92Mpa) and II(11.67MPa) respectively. SEM pictures of group II specimens clearly explain the underlying interaction at the tooth resin interface. It was observed that resin tags were fragmented and poorly defined and also penetrated to a lesser depth. Similar observations have also been reported by Titley and others in $2004{ }^{17-20}$

On evaluating the groups that were surface treated before bonding (Groups III, IV, V ), it is evident that all the experimental groups have performed significantly better than the control groups(Group I, II). This clearly indicates that surface treatment with these agents have resulted in improved shear bond strength of composite to bleached enamel surface. The SEM picture of the above specimen's showed evenly formed resin tags penetrating deeper into the enamel substrate. [fig 3]

Ascorbic acid and its salts have a proven safety record in the food industry for their use as antioxidants and are capable of reducing a variety of oxidative compounds, especially free radicals. It is probable that sodium ascorbate allows free radical polymerization of the adhesive to proceed without premature termination by restoring the altered redox potential of the oxidized bonding substrate, thus reversing the compromised bonding. ${ }^{21}$

The strong antioxidant activity of Pomegranate seed extract is attributable to a diverse group of polyphenols including ellagitannins, gallotannins, ellagic acid, and flavonoids such as anthocyanins.

Increased bond strength obtained in Group V (tomato seed extract) is attributed to the presence of Lycopene, ascorbic acid \&phenolics which possess high antioxidant properties.

Lycopene is a natural pigment accumulated in ripe tomatoes, watermelons, red chillies, and guavas, giving them their characteristic red colour. It exerts potent antioxidant and free radical scavenging properties. ${ }^{21}$

The results obtained in our study does not agree with the findings of study done by Mageshwaran et al. the authors have found that sodium ascorbate performed better than tomato extract. The reason attributed by them is that according to Lipinski's rule, molecular weight of the drug should be less than $500 \mathrm{~g} / \mathrm{mol}$ for its bioavailability. ${ }^{[1]}$ Sodium ascorbate has a molecular weight of $198.11 \mathrm{~g} / \mathrm{mol}$ and is water soluble. This could have enabled sodium ascorbate to penetrate better than lycopene. In the above study $5 \mathrm{gm}$ of tomato whole fruit extract in the form of a powder and dissolved in water to make 5\% lycopene solution. Where as in the current study, $5 \mathrm{gm}$ of tomato seed extract dissolved in distilled water to obtain 5\% solution. It has been demonstrated by Ramandeep $\mathrm{K}$ et al that the skin and seeds of tomato on average contributed $53 \%$ to the total phenolics, $52 \%$ to the total flavonoids, $48 \%$ to the total lycopene, $43 \%$ to the total ascorbic acid and $52 \%$ to the total antioxidant activity. ${ }^{22}$ Therefore it is possible that higher antioxidant activity of the tomato seed extracts might have resulted in better scavenging action and hence higher shear bond strength as demonstrated in our study.

It was also surprising to note that the bond strength values of Group III, IV,V was significantly higher than even the negative control group ( only composite without bleaching and surface treatment). This may be attributable to the acidic content of these agents- ascorbic acid in sodium ascorbate and tomato seed extract, ellagic acid in 
pomegranate seed extract might have caused double etching effect, resulting in deeper penetration of resin tags as evident in the SEM pictures However further research is essential to support and confirm the above. ${ }^{23}$

In our study, solution forms of the preparations were used. Gel forms are generally clinically easy to apply and are more potent. Although gel form of sodium ascorbate is available, the natural antioxidants in gel form have to be further formulated and evaluated for their efficacy.

It is also noteworthy to mention that the antioxidant solutions of pomegranate and tomato seed extracts being a dietary product, were straw coloured and yet did not produce any discoloration of the enamel which is one of the prerequisites for any agents to be used for surface treatment. One of the limitations of our study is that thermocycling has not been done. Perhaps bond strength testing after thermo-cycling may give more predictable results.

Based on the results obtained, it can be concluded that pomegranate and tomato seed extracts can be used as an alternative to sodium ascorbate as they have clearly indicated that surface treatment with these naturally available antioxidants increase the bond strength of composite restorations immediately after bleaching.
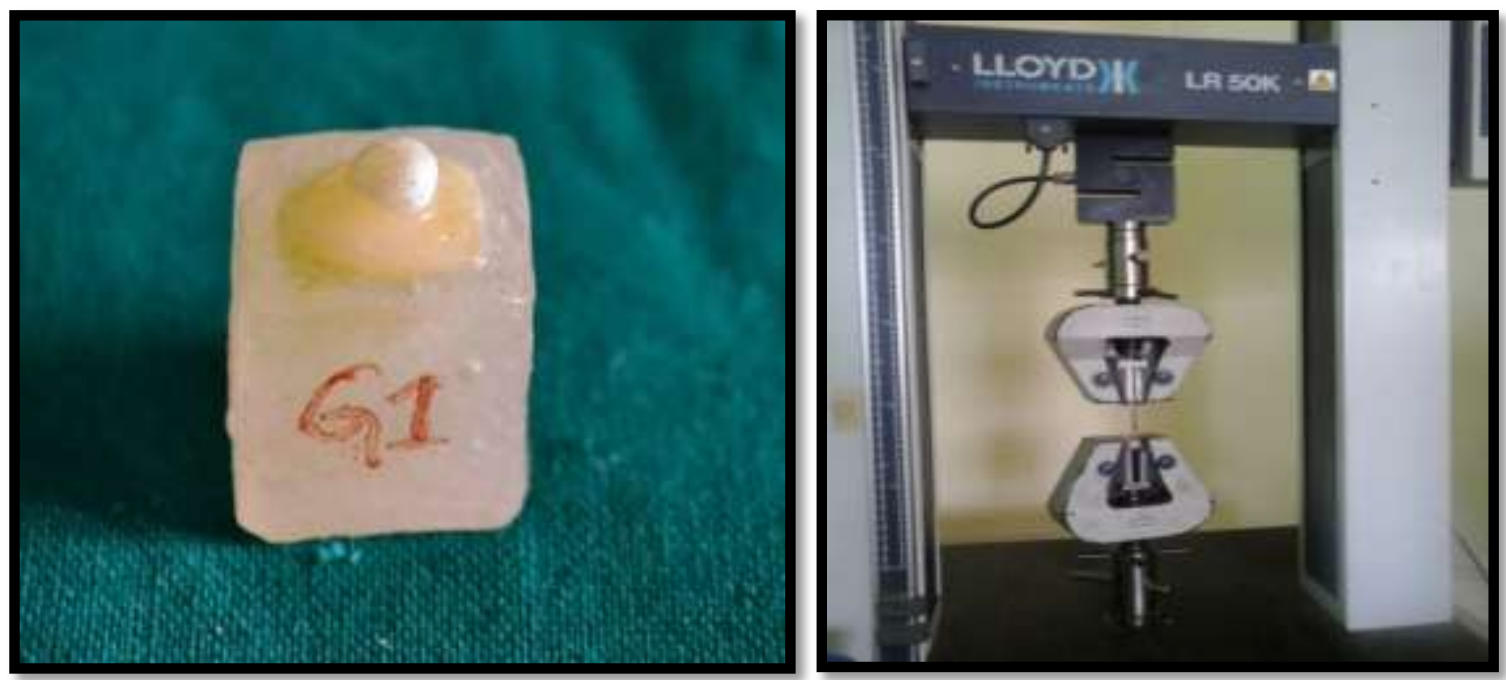

Fig.1- Tooth Mounted On Acrylic Block \& Composite Resin Build-Up Done

Fig.2- Specimen Mounted On Universal Testing Machine

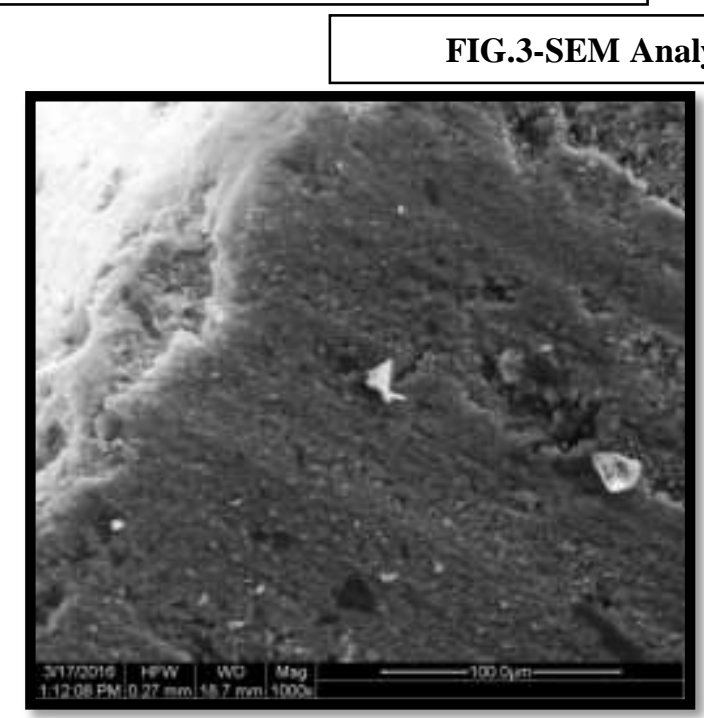

Fig.3.1:- Group I (No Bleaching, No Antioxidant Application)

FIG.3.2:- Group II (only bleaching, no antioxidant application) 


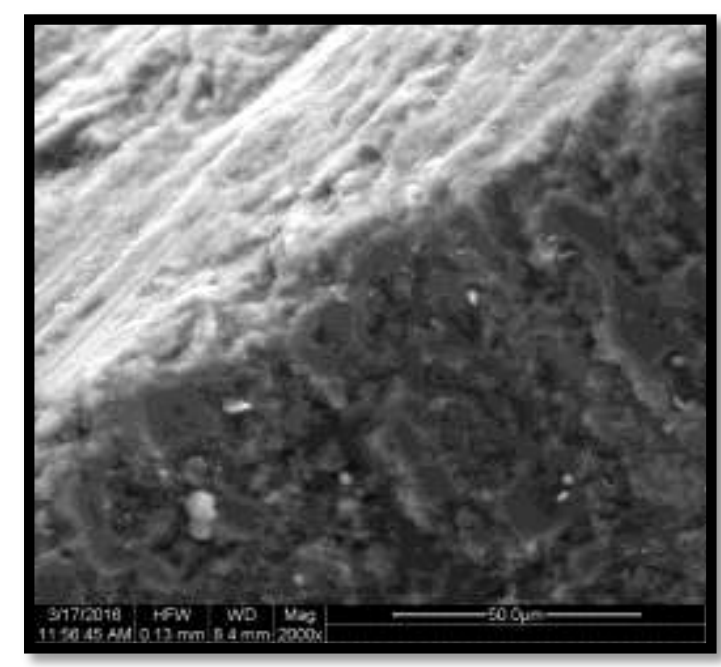

FIG.3.3- Group III- bleaching followed by sodium ascorbate application

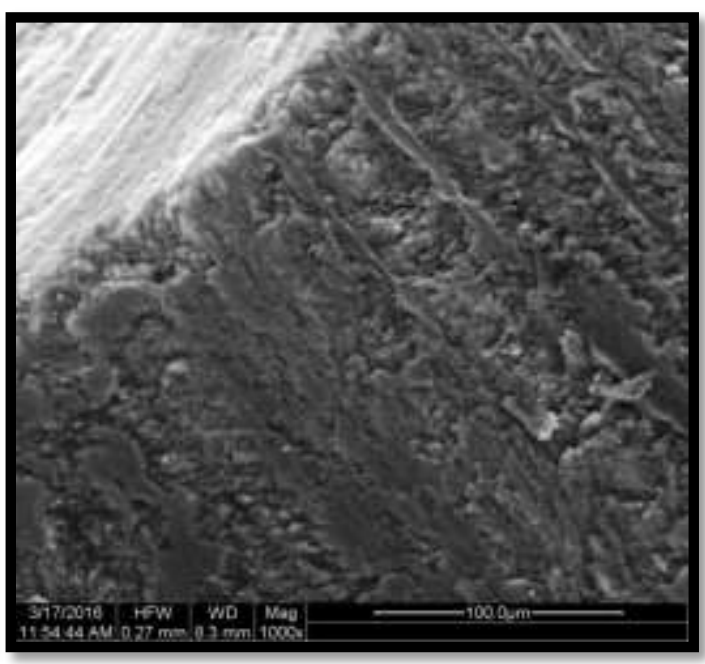

FIG.3.4- Group IV- Bleaching+ pomegranate seed extract application

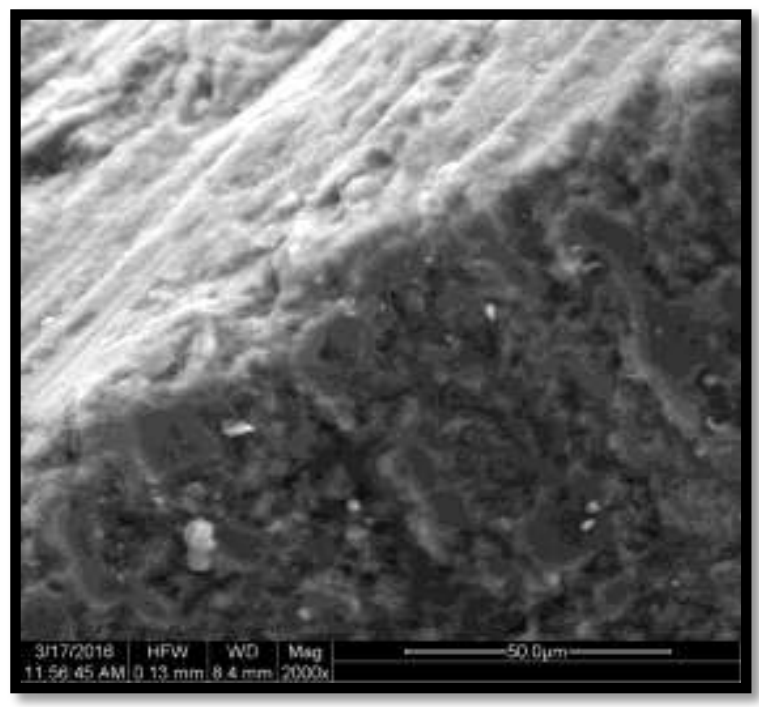

FIG.3.5- Group V- Bleaching + tomato seed extract application.

Result tables:

\begin{tabular}{|l|l|l|l|l|l|l|l|l|}
\hline Group & $\mathbf{n}$ & Mean & $\begin{array}{l}\text { Std. } \\
\text { Deviation }\end{array}$ & Std. Error & \multicolumn{2}{|l|}{ 95\% CI for Mean } & \multirow{2}{*}{ Min } & \multirow{2}{*}{ Max } \\
\cline { 7 - 9 } & & & & Lower Bound & Upper Bound & & \\
\hline Group I & 10 & 21.92 & 3.52 & 1.11 & 19.40 & 24.43 & 18.59 & 28.00 \\
\hline Group II & 10 & 11.67 & 3.01 & 0.95 & 9.52 & 13.83 & 6.81 & 16.69 \\
\hline Group III & 10 & 38.34 & 6.58 & 2.08 & 33.63 & 43.04 & 30.45 & 50.49 \\
\hline Group IV & 10 & 42.93 & 8.78 & 2.78 & 36.65 & 49.21 & 24.30 & 55.00 \\
\hline Group V & 10 & 43.50 & 5.57 & 1.76 & 39.51 & 47.48 & 33.97 & 50.23 \\
\hline
\end{tabular}

FIG:4:-Mean Shear Bond Strength recorded in the groups:

Higher mean Shear Bond Strength was recorded in Group V followed by Group IV, Group III, Group I and Group II respectively. The difference in mean Shear Bond Strength among the groups was found to be statistically significant $(\mathrm{p}<0.001)$. 


\begin{tabular}{|l|l|l|l|l|l|}
\hline Group (I) & Group (J) & $\begin{array}{l}\text { Mean Difference } \\
\text { (I-J) }\end{array}$ & p-Value & \multicolumn{2}{|l|}{ 95\% CI for Mean Difference } \\
\cline { 3 - 6 } & & 10.242 & $0.003^{*}$ & 2.48 & Lower Bound \\
\hline \multirow{5}{*}{ Group I } & Group II & -16.424 & $<0.001^{*}$ & -24.18 & -8.66 \\
\cline { 2 - 6 } & Group III & -21.012 & $<0.001^{*}$ & -28.77 & -13.25 \\
\cline { 2 - 6 } & Group IV & -21.581 & $<0.001^{*}$ & -29.34 & -13.82 \\
\cline { 2 - 6 } & Group V & -26.666 & $<0.001^{*}$ & -34.43 & -18.91 \\
\hline \multirow{5}{*}{ Group II } & Group III & -31.254 & $<0.001^{*}$ & -39.01 & -23.49 \\
\cline { 2 - 6 } & Group IV & -31.823 & $<0.001^{*}$ & -39.58 & -24.06 \\
\cline { 2 - 6 } & Group V & -4.588 & 0.877 & -12.35 & 3.17 \\
\hline \multirow{3}{*}{ Group III } & Group IV & -5.157 & 0.560 & -12.92 & 2.60 \\
\hline Group IV & Group V & -0.569 & 1.000 & -8.33 & 7.19 \\
\hline
\end{tabular}

*denotes significant difference

FIG 5:-Multiple comparisons using Bonferroni test

The difference in mean Shear Bond Strength was found to be statistically significant between Group I \& Group II ( $p<0.01)$, Group I \& Group III ( $p<0.001)$, Group I \& Group IV ( $<<0.001)$, group I \& Group V ( $<<0.001)$, Group II $\&$ Group III $(p<0.001)$, Group II \& Group IV $(p<0.001)$ as well as between Group II \& Group V ( $<<0.001)$. No significant difference was observed between Group III \& Group IV (p>0.05), Group III \& Group V (p>0.05) as well as between Group IV \& Group V ( $>0.05)$.

\section{Bibliography:-}

1. Vidhya S, Srinivasulu S, Sujatha M, Mahalaxmi S. Effect of grape seed extract on the bond strength of bleached enamel. Oper Dent 2011;36:433-8.

2. Briso AL, Toseto RM, Rahal V, Dos Santos PH, Ambrosano GM. Effect of sodium ascorbate on tag formation in bleached enamel. J Adhes Dent 2012;39:195-203.

3. Barghi N, Godwin JM. Reducing the Adverse Effect of Bleaching on Composite-Enamel Bond. J EsthetRestor Dent 1994;6:157-61.

4. Cvitko E, Denehy GE, Swift EJ, Pires JA. Bond strength of composite resin to enamel bleached with carbamide peroxide. J EsthetRestor Dent 1991;3:100-2.

5. Kalili T, Caputo AA, Mito R, Sperbeck G, Matyas J. In vitro toothbrush abrasion and bond strength of bleached enamel. Pract Periodontics Aesthet Dent 1991;3:22-4.

6. Hassimotto NM, Genovese MI, Lajolo FM. Antioxidant activity of dietary fruits, vegetables, and commercial frozen fruit pulps. J Agric Food Chem 2005;53:2928-35.

7. Sasaki RT, Flório FM, Basting RT. Effect of $10 \%$ sodium ascorbate and $10 \%$-tocopherol in different formulations on the shear bond strength of enamel and dentin submitted to a home-use bleaching treatment. Oper Dent 2009;34:746-52.

8. Lai SC, Tay FR, Cheung GS, Mak YF, Carvalho RM, Wei SH, Toledano M et al. Reversal of compromised bonding in bleached enamel. J Dent Res 2002;81:477-81.

9. Abraham S, Ghonmode WN, Saujanya KP, Jaju N, Tambe VH, Yawalikar PP. Effect of grape seed extracts on bond strength of bleached enamel using fifth and seventh generation bonding agents. J Int Oral Health 2013;5:101-7.

10. Dishman MV, Covey DA, Baughan LW. The effects of peroxide bleaching on composite to enamel bond strength. Dent Mat 1994;10:33-6.

11. Titley KC, Torneck CD, Smith DC, Chernecky R, Adibfar A. Scanning electron microscopy observations on the penetration and structure of resin tags in bleached and unbleached bovine enamel. J Endod 1991;17:72-5.

12. Wenli Y, Yaping Z, Zhen X, Hui J, Dapu W. The antioxidant properties of lycopene concentrate extracted from tomato paste. J Am Oil ChemSoc 2001;78:697-701.

13. Sharafeddin F, Motamedi M, Modiri S. Effect of Immediate Application of Pomegranate Peel, Grape Seed and Green Tea Extracts on Composite Shear Bond Strength of In-Office Bleached Enamel. Res J Bio Sci 2013;8:837.

14. Arumugam MT, Nesamani R, Kittappa K, Sanjeev K, Sekar M. Effect of various antioxidants on the shear bond strength of composite resin to bleached enamel: An in vitro study. J Conserv Dent 2014;17-22.

15. Dabas D, Patil AC, Uppin VM. Evaluation of the effect of concentration and duration of application of sodium ascorbate hydrogel on the bond strength of composite resin to bleached enamel. J Conserv Dent 2011;14:356. 
16. Sharafeddin F, Jamalipour GR. Effects of 35\% carbamide peroxide gel on surface roughness and hardness of composite resins. J Dent [Tehran] 2010;7:6-12.

17. DiliniBopitiya ,TerrenceMadhujith; Antioxidant Potential of Pomegranate (Punica granatum L.) Cultivars ; Trop Agri Res 2012;24: $71-81$.

18. Titley KC, Torneck CD, Ruse ND. The effect of carbamide-peroxide gel on the shear bond strength of a microfil resin to bovine enamel. J Dental Res 1992;71:20-4.

19. Türkün M, Kaya AD. Effect of $10 \%$ sodium ascorbate on the shear bond strength of composite resin to bleached bovine enamel. J Oral Rehabil 2004;31:1184-91.

20. Silva-Beltrán NP, Ruiz-Cruz S, Cira-Chávez LA, Estrada-Alvarado MI, Ornelas-Paz JD, López-Mata MA et al. Total phenolic, flavonoid, tomatine, and tomatidine contents and antioxidant and antimicrobial activities of extracts of tomato plant. Int J Anal Chem 2015;39:195-203.

21. Kimyai S, Oskoee SS, Rafighi A, Valizadeh H, Ajami AA, Helali ZN. Comparison of the effect of hydrogel and solution forms of sodium ascorbate on orthodontic bracket-enamel shear bond strength immediately after bleaching: an in vitro study. Ind J Dent Res 2010;21:54.

22. Ramandeep K, Savage GP. Antioxidant activity in different fractions of tomatoes. Food Res Int 2005;38:48794.

23. Muraguchi K, Shigenobu S, Suzuki S, Tanaka T. Improvement of bonding to bleached bovine tooth surfaces by ascorbic acid treatment. Dent Mat J 2007;26:875-81. 